\title{
TRAFFIC INFORMATION INTERFACE DEVELOPMENT IN ROUTE CHOICE DECISION
}

\section{Md. Saidul Azam Chowdhury ${ }^{1}$, Md. Bashirul Haque ${ }^{2}$ and Golam Sarwar ${ }^{3}$}

\author{
${ }^{I}$ Department of Civil and Environmental Engineering, Shahjalal University of Science and Technology \\ Sylhet, Bangladesh \\ Phone:+8801717189361.E-mail:tuhin_st7@yahoo.com \\ ${ }^{2}$ Department of Civil and Environmental Engineering, Shahjalal University of Science and Technology \\ Sylhet, Bangladesh \\ Phone: +8801913409490. E-mail: bashir_cee@yahoo.com \\ ${ }^{3}$ Department of Civil and Environmental Engineering, Shahjalal University of Science and Technology, \\ Sylhet, Bangladesh \\ Phone:+8801722248000.E-mail: smiley.tushar@gmail.com
}

\begin{abstract}
In this paper, a method has been developed based on historic traffic data (vehicle speed), which helps the commuters to choose routes by their intelligence knowing the traffic conditions in Google maps. Data has been collected on basis of video analysis from several segments between Tuker Bazar and Bandar Bazar route. For each of the video footage, a reference length has been recorded with measurement tape for use in video analysis. Software has been also developed based on Java language to get the traffic information from historic data, which shows the output as images consisting of traffic speed details on the available routes by giving day and time limit as inputs. The developed models provide useful insights and helpful for the policy makers that can lead to the reduction of traffic congestion and increase the scope of intelligence of the road users, at least for the underdeveloped or developing country where navigation is still unavailable.
\end{abstract}

Keywords: traffic speed, speed interface, route choice, Google maps, Java, Kinovea

\section{Introduction}

Traffic congestion is a notable transportation related problems in Bangladesh. This problem is becoming a prominent problem in Sylhet city, the fifth populous city in Bangladesh (BBS, 2011) with a population more than 0.6 million and an area of only $26.5 \mathrm{~km}^{2}$. This city is facing rapid urbanization problem because of large amount of people's migration with unimproved transportation facilities (Haque, 2008), the leading reason behind rapid increase in congestion. Tuker Bazar to Bandar Bazar is one of the busiest and congestive routes in Sylhet city.

The urban transport issues of mobility, congestion, safety and environmental aspects are becoming increasingly important and critical while the rapid urbanization process, high vehicular population growth, inadequate transportation facilities and policies, varied traffic mix with an over concentration of non-motorized vehicles, absence of dependable public transport system and inadequate traffic management practices have created a significant worsening of traffic and environmental problems in the major urban areas (Haque, 2011).

Generally people choose routes from alternatives with the knowledge of experience on that specific road condition on a specific time range. The capacity of the roadways is not sufficient to transport all car drivers without delay, especially in the rush hours when there are enormous traffic jams. Therefore, a method has been developed in this paper based on historical traffic data, which helps the drivers or commuters to learn the traffic flow condition of specific time span, and, thus, helps to choose routes by their intelligence knowing the traffic conditions. An overview has been proposed to show the traffic data and traffic condition in basis of vehicle speed.

\section{Literature Review}

Traffic information collection and providing it to the commuters for their route choice is an important part of intelligent transportation system. Vast researches are being made on this sector worldwide. Tong et al. (2006) described an integrated GPS-GIS methodology for traffic information data 
extraction. The spatial characteristics for the highways of interest were developed using a GIS based on the Franklin County DOQQ with a high resolution of $0.5 \mathrm{ft} .(0.15 \mathrm{~m})$. Linear referencing, which is used by highway professionals to express a location as a distance from a known starting point in a given direction, was also used in the GIS. Chen et al. (2010) proposed path observation generation algorithm, supplemented to a path probability measurement in their paper to generate path observations from GPS data. By applying to real trips, they showed the viability of the algorithm and analyzed some characteristics of the algorithm in order to explore any possibility of improving it. Tatomir et al. (2009) discussed the problem of dynamic routing in their paper. They adapted the ABC algorithm and were able to compute the shortest path in time taking into account travel time predictions along road segments. They combined it with historical data from ANWB containing speed measurements along the freeways in the Netherlands. Anwar and Chowdhury (2007) presented a complete Transport Information System that facilitates the travellers to choose their comfortable transport, reduce ravel time by guiding them to travel through a shortest path to go their desired destination. Abbass (2010) used image processing to estimate car speed, given a sequence of real-time video of traffic images. The images are converted to monochrome images then edges are extracted and then quantified the resulting images to classify the objects and find the cars, after detecting the cars, they can be tracked in different frames and their speed can be estimated by calculating the position of the car object in different frames and compare it to a ground truth. His research used a different approach to estimate speed, rather than using a reference object to estimate speed, the MATLAB function is used and different relationships between the objects that are extracted from the image itself.

Mehrubeoglu and McLauchlan (2009) used optical flow patterns and blob analysis for vehicle detection and tracking. Yu et al. (2002) describes an algorithm that estimates traffic density and average speed from Skycam MPEG compressed images. Kimsey (2010) showed time and distance analysis to calculate speed of a patrol car from a videos tape of 29.97 frames per second in which a still picture is recorded every 0.0333 seconds.

Gathering inspiration from Google traffic map, in this paper an interface for traffic information (speed) is being tried to be developed. Google maps shows traffic information by collecting GPS enabled handset data to help the commuters make their choice to choose the route or change their current route for any kind of incident such as congestion, traffic flow volume etc. In this context, Java language based software has developed, which will show the traffic condition (via traffic speed) on Google maps, which will be a guideline for the developing countries where navigation is still unavailable.

\section{Methodology}

A traffic information interface based on vehicle speed has been developed for easier route choice decisions as well as a software output based on Java language. Tuker Bazar to Bandar Bazar route has been chosen. Three roads are used mainly to travel this route which is via Medical road, Police line road and Amberkhana and have fifteen road segments. Existing roadway of this route are shown on Figure 1.

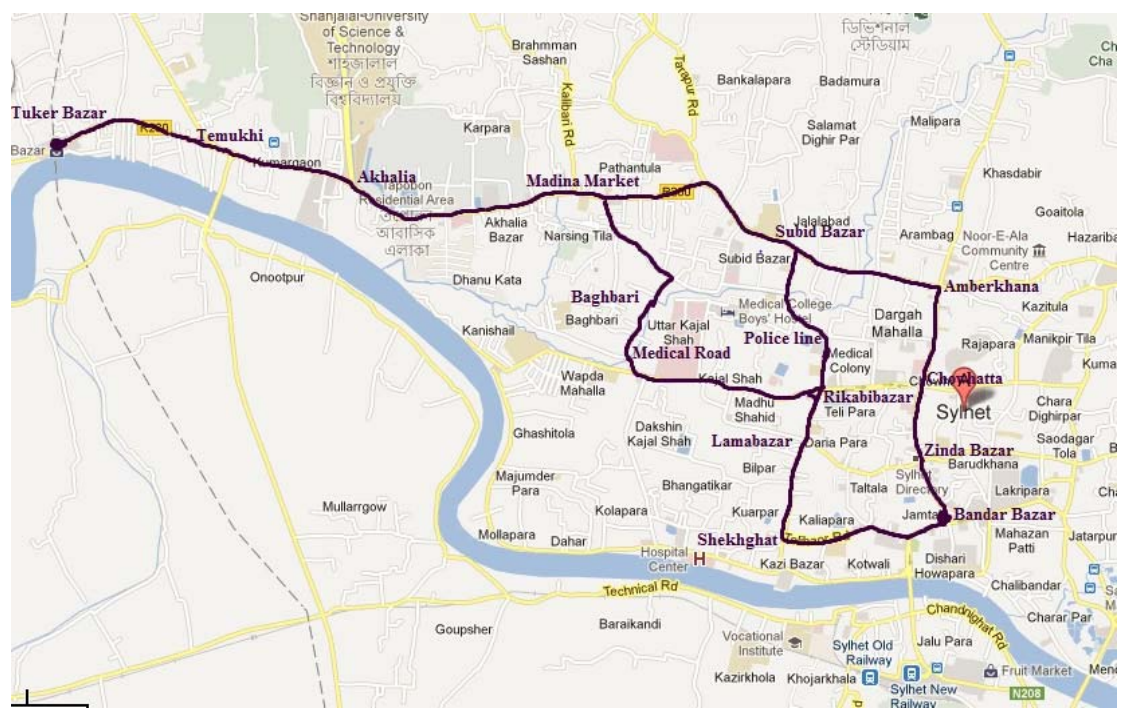

Figure 1. Study area (Source: http://maps.google.com/) 
At first, stations are selected to collect the video footages. On each station video of 15 minutes for each hour is made keeping the road perpendicular to the video camera. Several video footages are collected from each road segments available from Tuker Bazar to Bandar Bazar. Hourly data have been taken from 9:00 AM to 10:00 AM and 4:00 PM to 5:00 PM of Sunday only. For each of the video footage, a reference measurement length has been recorded with measurement tape for use in video analysis. The recorded videos are analyzed with the help of biomechanical video analyzing software named Kinovea. Video footages are calibrated by the reference measurement that was recorded during data collection. The video footages are of 29.97 Frames per second. The videos are made of slow motion to detect frame by frame images to realize the movements of vehicles in time. Then from an easy velocity calculation $(\mathrm{V}=\mathrm{D} / \mathrm{t})$ the speed is measured (Kimsey, 2010). Using this speed variation data, an interface has been developed which will show the traffic condition with speed limits by denoting different colours. Software has been developed based on Java language to get the output more easily to the commuters.

\section{Data Analysis}

Traffic speed has been calculated from collected video footages by the software named Kinoviea and the speeds were found automatically from the software. Then this speed was calculated by video analysis calculation and have been compared both findings. In this paper only Sunday and 9:00AM10:00AM and 4:00PM-5:00PM have been taken as the busiest day and time of the week.

An example has been shown here how the traffic speed of a specific route has been calculated. The example video footage was taken at Shahjalal University Gate area of Sylhet-Sunamgonj Highway Road. A reference measurement of 9.39 meters between two billboard poles has been taken. A CNG taxi was just about to cross the first pole from the right side when it was found, Frame no: 363 and Time: 0:00:12:07 that means 12.07 seconds (Figure 2). When the taxi was about to cross the left sided second pole crossing 9.39 meters the calculated Frame no: 391 and Time: 0:00:13:01 that means 13.01 seconds (Figure 3).

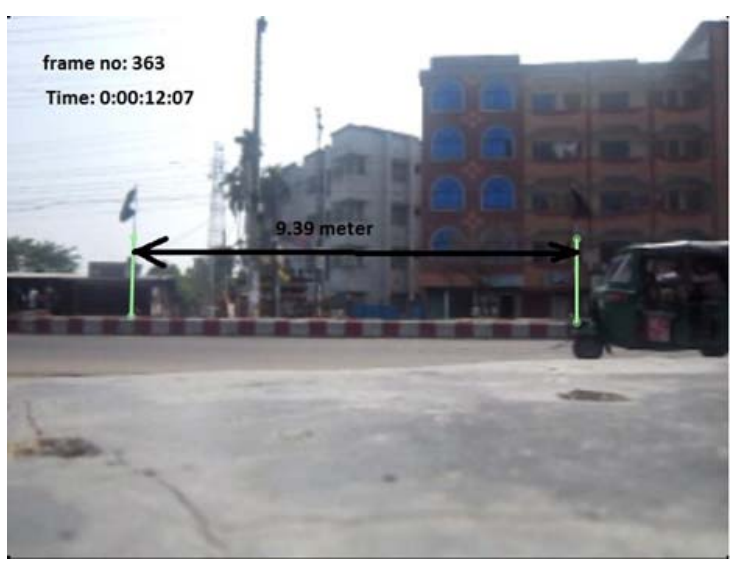

Figure 2. Taxi about to cross first pole

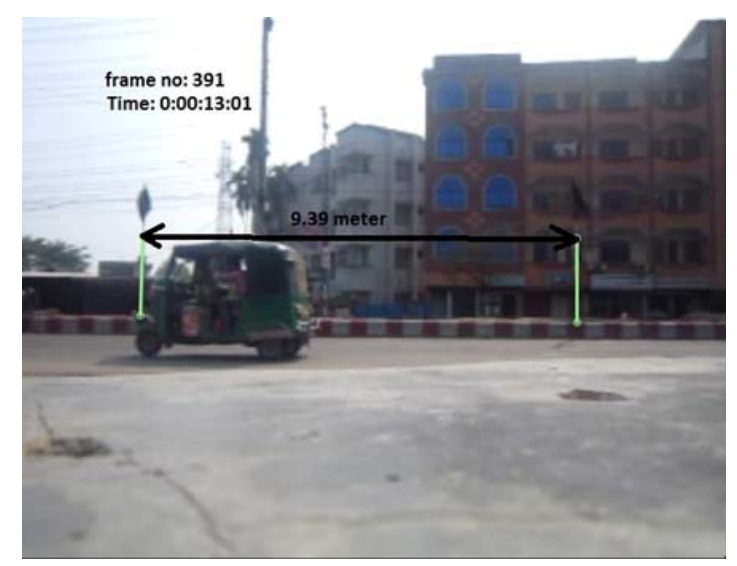

Figure 3. Taxi about to cross second pole

Now using conventional formula,

Distance Travelled by the CNG Taxi,

$\mathrm{D}=9.39$ meters

Time to cross the above mentioned distance,

$$
\mathrm{t}=(13.01-12.07)=0.94 \text { seconds }
$$

So, Speed of the CNG Taxi,

$$
\begin{aligned}
& \mathrm{V}=\mathrm{D} / \mathrm{t}=9.39 / 0.94 \\
& =9.9894 \text { meter per second } \\
& =35.96 \text { kilometre per hour } \\
& \approx 36 \mathrm{~km} / \mathrm{h}
\end{aligned}
$$


And from the same vehicle, from Kinovea output, it was found $36.22 \mathrm{~km} / \mathrm{h} \approx 36 \mathrm{~km} / \mathrm{h}$. Figure 4 shows the software output.

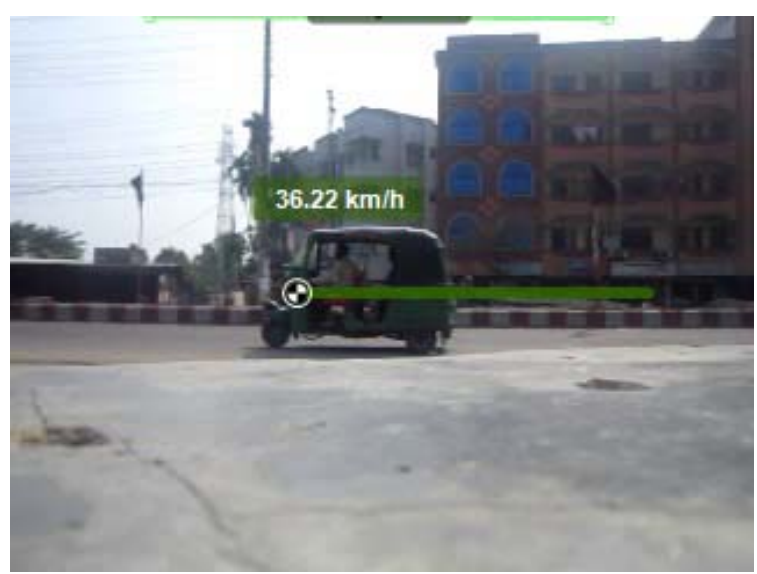

Figure 4. Taxi speed from Kinovea

Hence the speed limit have been taken of that road is between $30 \mathrm{~km} / \mathrm{h}$ to $40 \mathrm{~km} / \mathrm{h}$.

This way all the roads traffic speed of two specific time limits and a day has been calculated and shown in Table 1.

Table 1. Speed details for Sunday 9:00AM-10:00AM and 4:00PM-5:00PM $(\mathrm{km} / \mathrm{h})$

\begin{tabular}{lcc}
\hline Road Segment & 9:00AM-10:00AM & 4:00PM-5:00PM \\
\hline Tuker Bazar-Temukhi & $40-50$ & $40-50$ \\
\hline Temukhi-Akhalia & $50-60$ & $40-50$ \\
\hline Akhalia-Madina market & $30-40$ & $30-40$ \\
\hline Madina market-Baghbari & $10-20$ & $20-30$ \\
\hline Baghbari-Medical & $20-30$ & $20-30$ \\
\hline Medical-Rikabibazar & $20-30$ & $10-20$ \\
\hline Rikabibazar-Lamabazar & $20-30$ & $10-20$ \\
\hline Lamabazar-Shekhghat & $30-40$ & $20-30$ \\
\hline Shekhghat-Bandar Bazar & $30-40$ & $20-30$ \\
\hline Madina market-Subid Bazar & $30-40$ & $20-30$ \\
\hline Subid Bazar-Rikabibazar & $30-40$ & $20-30$ \\
\hline Subid Bazar-Amberkhana & $20-30$ & $0-10$ \\
\hline Ambarkhana-Chouhatta & $20-30$ & $0-10$ \\
\hline Chouhatta-Zinda Bazar & $20-30$ & $0-10$ \\
\hline Zinda Bazar-Bandar Bazar & $20-30$ & $0-10$
\end{tabular}

\section{Model Development}

The motive to collect the speed of traffic vehicles is to make them available to the commuters so that they can make choice which route to be selected when generating a trip. For this reason an interface development is required by which travellers can learn about the traffic condition on the routes available. An interface has been developed, a small Java based software to show the traffic condition on a specific day in a time limit. By this software a commuter can input the DAY and TIME LIMIT and the output will show an image consisting of traffic speed details on the routes available from Tuker Bazar to Bandar Bazar. The colours to express the speed limits are as follows in Table 2.

Table 2. Colours defining the speed limits

\begin{tabular}{|c|c|}
\hline Colour & Speed $(\mathbf{k m} / \mathbf{h})$ \\
\hline & $0-10$ \\
\hline & $10-20$ \\
\hline & $20-30$ \\
\hline & $30-40$ \\
\hline & $40-50$ \\
\hline & $50-60$ \\
\hline
\end{tabular}


The outputs of the software for these two time limits 9:00am-10:00am and 4:00pm-5:00pm of Sunday are given below:

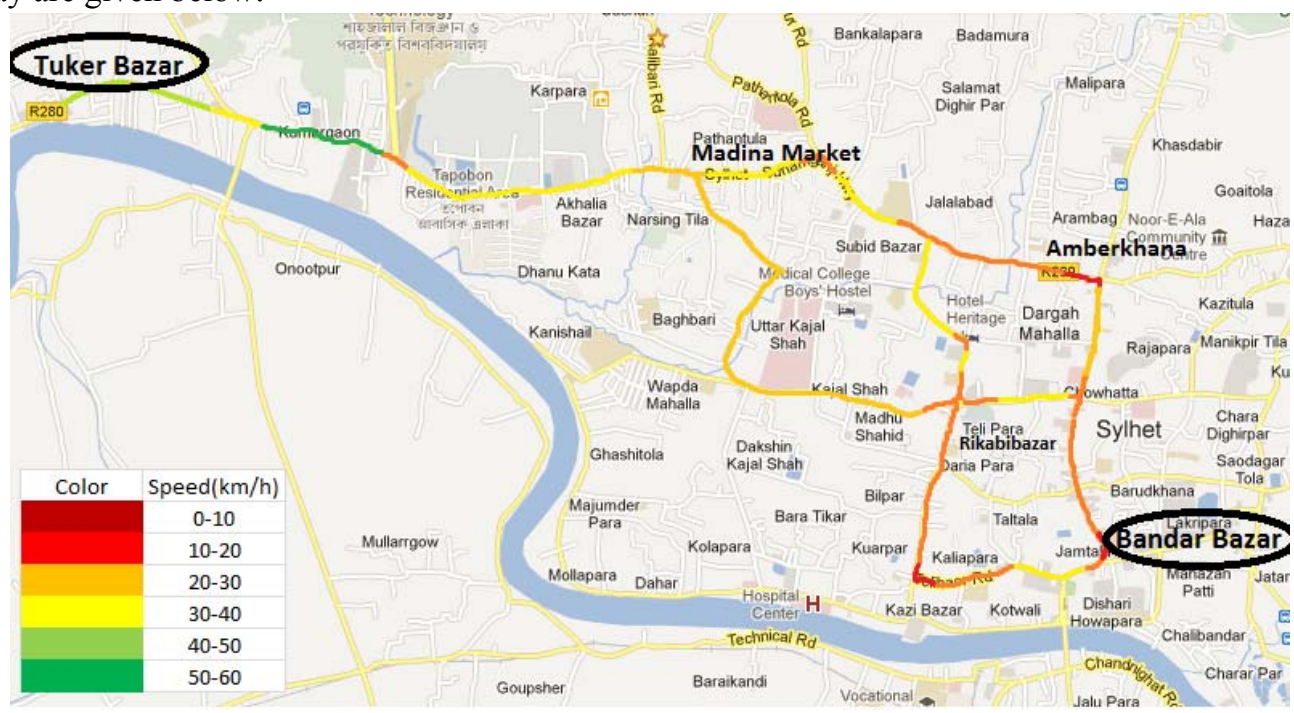

Figure 5. Speed limit details (Sunday, 9:00am-10:00am) on map for the routes from Tuker Bazar to Bandar Bazar

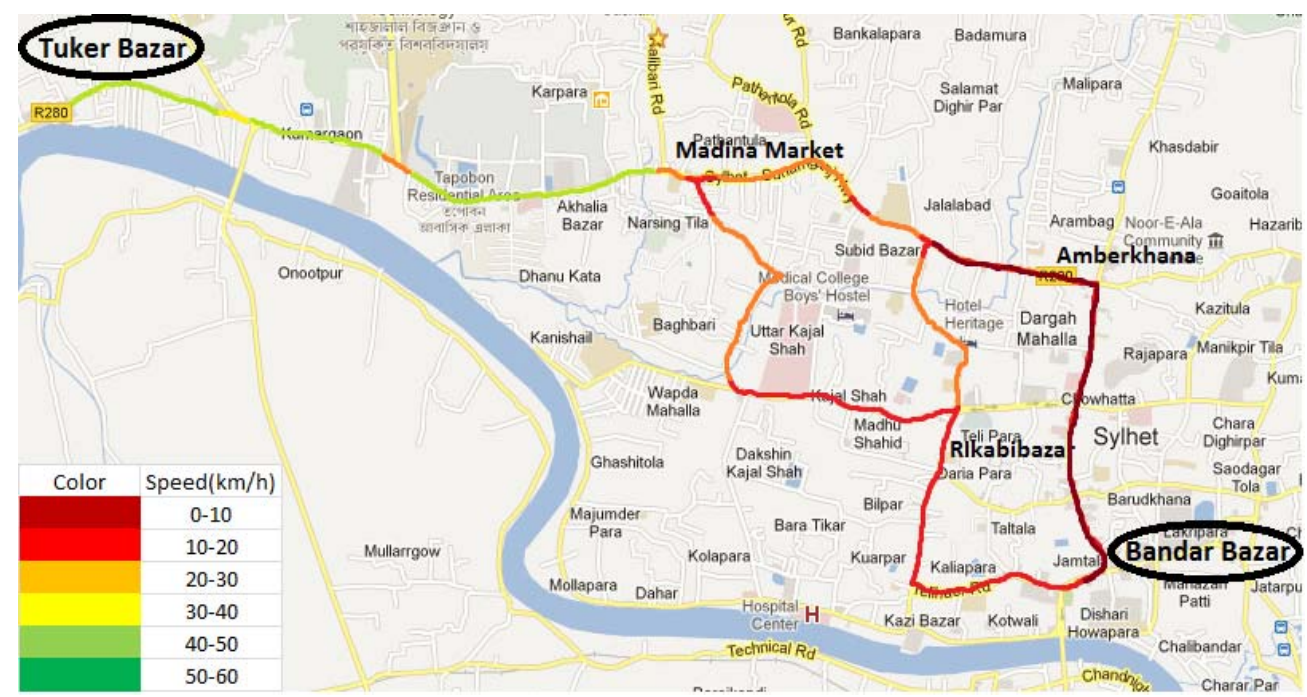

Figure 6. Speed limit details (Sunday, 4:00pm-5:00pm) on map for the routes from Tuker Bazar to Bandar Bazar

It was found that can be seen on Figure 5 that almost all the routes have moderate flow, but medical road is comparatively with smooth flow than other two routes; and Figure 6 shows that Medical road or Police line road is better to be chosen as Amberkhana link is with traffic congestion. This helps a commuter to choose the routes before starting his journey with this information. The developed software can be used in computer and mobile phones to collect traffic information by commuters.

\section{Conclusions}

A conceptual method in Google maps for showing traffic information based on vehicle speed and a Java based software to get the output more easier to the commuters have been developed in this study. First, vehicle speed has been calculated from both Kinovea and conventional formula and a speed range has been denoted with different colours. Second, a Java based software has been developed to find the output of traffic condition in Google maps by giving input "DAY" and "TIME LIMIT", which can be used in computer as well as commuters mobile phone. In a developing country like Bangladesh has not yet been introduced to any advanced technology such as sensors, speed detecting camera and many powerful 
software and their database to collect traffic information and reach them to travellers in real time, navigation etc., although traffic congestion is a major concern in this country.

There were so many limitations and disadvantages by doing this research. The most highlighting problems were that collecting so many video footages with normal video camera is difficult and time consuming. With this developed method it is not possible to provide real time traffic information whether only historic data is available. It would be better if it is possible to use speed detecting devices like sensors or speed cameras to collect the traffic speed data. For limited time and due to many reasons all the traffic speed data for other days could not be collected. This may be expanded by taking data of 24 hours, at least morning to night of whole week as well as whole month. In Bangladesh, setting up traffic sensors, camera or other technical devices traffic information's can be collected in near future. And a route user will be able to know about traffic condition even before starting his journey. But still the developed method is an attempt to collect the speed data of routes, which might be helpful if it is well developed, regularly updated and available to people.

\section{References}

1. Abbass, A. (2010). Estimating vehicle speed using image processing. AL-Mansour Journal, 14/Special Issue, (Part Two).

2. Anwar, S. \& Chowdhury, D.M. (2007). Transport information system. [Online] http://hdl.handle.net/10361/196.

3. BBS. (2011). Bangladesh Bureau of Statistics, Ministry of Planning, Government of the People's Republic of Bangladesh.

4. Chen, J., Newman, J. \& Bierlaire, M. (2009). Modeling route choice behavior from smart-phone GPS data. In Proceedings of the $12^{\text {th }}$ International Conference on Travel Behaviour Research (IATBR), pp. 13-18.

5. Haque, M.B. (2011). Developing a Combined Residential Location and Transport Mode Choice: Model Using RP and SP Data. M.Sc. Thesis, Department of Civil Engineering, BUET, Dhaka.

6. Haque, M.B. (2008). Development of an Urban Transport Model Using the Existing Traffic Condition in Sylhet City. B.Sc. Thesis, Department of Civil and Environmental Engineering, SUST, Sylhet.

7. Kimsey, M. (2010). Speed Calculation from a Video Tape. Accident Reconstruction Newsletter, 12(101).

8. Mehrubeoglu, M. \& McLauchlan, L. (2009). Determination of vehicle speed in traffic video. In IS \& T/SPIE Electronic Imaging (pp. 72440O-72440O). International Society for Optics and Photonics.

9. Tatomir, B., Rothkrantz, L.J. \& Suson, A.C. (2009). Travel time prediction for dynamic routing using ant based control. In Proceedings of the Winter Simulation Conference (WSC), 2009 (pp. 1069-1078). IEEE.

10. Tong, D., Merry, C.J. \& Coifman, B. (2006). Traffic information deriving using GPS probe vehicle data integrated with GIS. In GIS for Transportation Symposium (pp. 27-29).

11. Yu, X.D., Duan, L.Y. \& Tian, Q. (2002). Highway traffic information extraction from Skycam MPEG video. In Proceedings of the IEEE 5th International Conference on Intelligent Transportation Systems (pp. 37-42). 